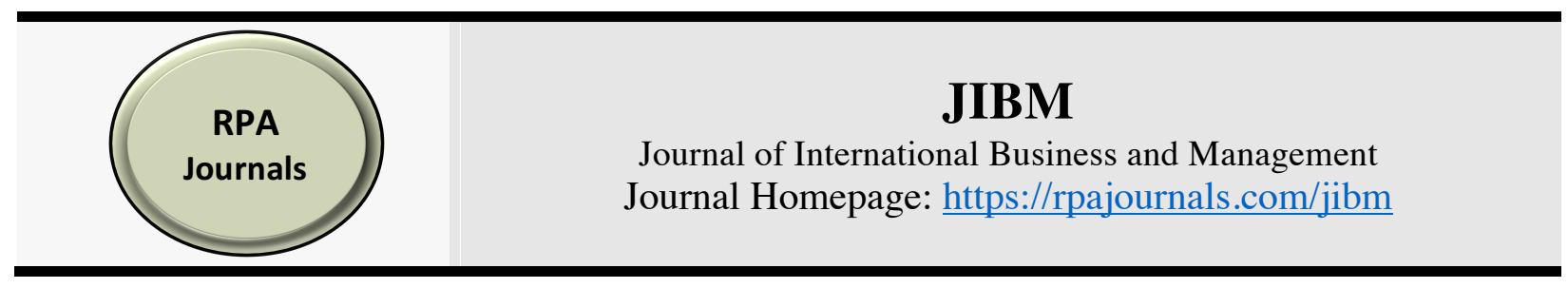

\title{
Impact of Perceived Ease of Use, Awareness and Perceived Cost on Intention to Use Solar Energy Technology in Sri Lanka
}

\author{
U. C. Bandara" \\ T.S.M. Amarasena \\ Ceylon Electricity Board, Sri Lanka' \\ University of Sri Jayewardenepura, Sri Lanka ${ }^{2}$
}

\begin{abstract}
Solar Energy acceptance and slow growth among households is a major issue in Sri Lanka. The aim of this study is to identify the impact of perceived ease of use, awareness of the technology and perceived cost over intention to use solar energy technology in Sri Lanka. Technology acceptance model (TAM), diffusion of innovation (DOI) and transaction cost economies theory (TCE) have been used to develop the research base. A self-administrated questionnaire was used to collect data from a sample of 384 respondent households. Structural Equation Modeling (SEM) was used to test three hypothesis. The results of the study indicates that perceived ease of use, awareness of the technology and perceived cost have a significant impact on solar energy technology adoption. The study enhances knowledge on solar energy as a power source of green energy for small scale households in urban areas. These findings can be used for strategic planning to ensure sustainable business growth as well as policy and decision making.
\end{abstract}

Keywords: Adoption, Awareness, Ease of Use, Perceived Cost, Solar Energy Technology

*Corresponding author: T.S.M. Amarasena; Email: sudath@sjp.ac.lk

DOI: https://doi.org/10.37227/jibm-2020-04-61

\section{Introduction}

To preserve the ecological balance of this planet, it is necessary to motivate users to opt for renewable energy technologies. Rapidly increasing energy demand and growing concerns are gradually pushing the world to the use of Renewable Energy sources. There are three generations of hydro power namely first, second and third. Hydropower, biomass combustion, and geothermal energy which are referred to as matured renewable energy technologies are categorized in to generation one. Fast growth renewable energy technologies are considered as the second generation, and it consists of solar, wind, and newfashioned bio-energy. The third generation consists with a wide range of renewable energies as concentrating solar power, ocean energy, modern geothermal energy, and integrated bioenergy. (IEA, 2006).

Many experts consider solar energy as one of the most promising technologies among them all. Solar energy is derived from the sun through the form of solar radiation and it is 
the most abundant energy source on earth. The sun is a very reliable, pollution free, renewable source of energy. Sustainable energy is a highly interesting and innovative concept which needs serious attention as energy costs are always on the rise, the human population is increasing, the environment is being polluted, and resources are being depleted. At the global level, renewables represented approximately $58.5 \%$ of net additions to global power capacity in 2014, with significant growth in all regions (Purohit, et al., 2017). The International Energy Agency (IEA) estimated that in 2050, about $11 \%$ of electricity production would be provided by solar energy worldwide (Katinas, et al., 2013). Sri Lanka's annual average solar irradiation is in the range of $5.5 \mathrm{KWhm}^{-2} \mathrm{~d}^{-1}$ and throughout the year with low seasonal variations. The solar irradiation that arrives at ground level depends mainly on the day of the year, the latitude of the location and on atmospheric transmittance, also termed as clearness index $\mathrm{K}_{\mathrm{r}}$ (Department of Meterology, 2016). Since Sri Lanka is a country near the equator getting sunlight throughout the year without much seasonal variations, we have much possibility of using Solar Energy throughout the year without interruption.

As a power utility of the country the Ceylon Electricity Board (CEB) has promoted electricity generation using Renewable Energy Resources since early nineties. Required assistance was provided to the private sector alone with training \& capacity building, prefeasibility studies and resource assessments. (Sustainable Energy Authority, 2011). Sri Lanka is reaching its $100 \%$ electrification target on 2018 and now it is almost $98.4 \%$ of the whole country's population. Compared to most of the South Asian Countries Sri Lanka have the most reliable grid electricity supply among them.

Studying the factors affecting the adoption with solar energy implementation in households in Sri Lanka is a contemporary issue which needs to be addressed due to global requirements and the energy crisis. Fuel diversifying and energy security in the generation of electricity was identified as a strategic objective and development of renewable energy projects was identified as a part of this strategy in the National Energy Policy 2006. (Sustainable Energy Authority, 2017) Introducing solar panels to the existing electricity users will be big a challenge. But considering the upcoming energy crisis we have a duty to move to solar energy and find the factors which are more considerably affecting the adoption with its technology. There are three main research questions addressed in this study. They are respectively addressed to observe the impact of perceived ease of use, awareness of the technology and perceived cost with respect to the intention of adopting solar energy technology in Sri Lanka.

\section{Background}

\section{Literature Review}

The devices that convert daylight without delay into power are called solar photovoltaics (PV) or solar cells or simply PV. In the year of 1954, the modern shape of the solar cell was invented at Bell Telephone Laboratories. The conversion of light (photons) to electricity (voltage), is a physical technique of is the term "photovoltaic" impact and it is so-referred to as "PV impact". (Taylor, et al., 2014). Global PV production ability was exceeded as much as $500 \mathrm{~kW}$ within the year of 1997 . Total installed solar PV capacity changed into $2 \mathrm{GW}$ and in year 2002, and 10 years later, in 2012, it exceeded $100 \mathrm{GW}$. New additions of Photo Voltaic solar cells in 2013 came alone with $39 \mathrm{GW}$ and according to the Tylor et al, for the first time it exceeded the new capacity additions of wind in a given year. Year 2014 was estimated as the year with records according to Tylor et al, with total installed PV capacity of $180 \mathrm{GW}$ at the end of the year world widely. (Taylor, et al., 2014). 


\section{Sri Lankan Energy Situation}

By the end of the year 2014, 98.4\% of the households in the Sri Lanka was electrified. The average per capita electricity consumption increased to 540 units from 519 units $(\mathrm{kWh} /$ person) in the previous year thus recording an increase of 21 units. (Ceylon Electricity Board, 2014). The total electricity sales during the year increased from $10,621 \mathrm{GWh}$ in the previous year to $11,063 \mathrm{GWh}$ which was a percentage increase of $4.2 \%$. The average daily consumption of electricity in the year was $30.3 \mathrm{GWh}$ as against $29.1 \mathrm{GWh}$ in the year 2013 . The trend of using renewable energy sources has increased with time to a considerable amount. Among the renewable energy sources, solar power is the most common method used is Sri Lanka. Meanwhile in solar Energy, installed capacity in megawatts as well as the number of solar connections have increased. Renewable energy usage to produce electricity in Sri Lanka was limited to large investors a few years ago, because it usually costs millions of rupees. But with the introduction of the "Net Metering" concept by 2008, the opportunity to produce electricity using renewable energy was possible even for small investors and it was open to all electricity customers in Sri Lanka.

The net metering concept or solar energy reduces the stress on distribution systems. Introducing the solar energy metering concept can eliminate the losses in lengthy electricity transmission lines, improves the constancy of the grid supply frequency and improves the distribution voltage profile.

\section{Factors Influencing Adoption of Solar Power Systems}

\section{Perceived Ease of Use}

Ease of use can be defined as the degree to which users easily understand, operate and maintain a new technology. Ease of public use of renewable energy can be ensures by using an effective quality control mechanism and by understanding the living standards of the target group. (Fishbein, et al., 1975). Wider public support and use of renewable energy are possible if users find the technology to be user-friendly, family-friendly and identical to their standard of living (Seyal, et al., 2006). Technology acceptance model (TAM) suggests that user's acceptance of new technology is based on their perceived ease of use. Ease of use is explained from the technical standpoint of renewable energy. Stephen and Ioannou have argued that family and community friendly renewable technology will positively influence the intention to use renewable energy.

\section{Awareness of the Technology}

The degree to which users are conscious of the current new technology and its benefits and weaknesses can keep track of updates on new technologies. Awareness is one of the key issues in adoption. Creating awareness of the product is important to the customer. (Fishbein, et al., 1975) Information gap makes the acceptance of new technology much less likely (Zografakis, et al., 2010). Adoption can be defined as the acceptance and continued use of a product, service or idea. According to Rogers and Shoemaker consumers go through "a series of processes in knowledge, conviction, decision and confirmation" before they are ready to adopt a new product or service. (Rogers , et al., 2001) The adoption or rejection of an innovation begins when "the consumer becomes aware of the innovation" (Rogers , et al., 2001). Howard and Moore stressed that in adoption, "consumers must become aware of the new brand." (Howard, et al., 2002). More knowledgeable consumers are assumed to be more willing to adopt. 


\section{Perceived Cost}

The cost of Renewable energy incorporates both a holistic outlook on the initial requirement to set up the machines as well as their periodic costs. Higher the cost of the technology, the lower its value to users, and lower its rate of usage (Premkumar, et al., 1997). Price/costs is one of the single most important factors that influences consumer adoption of innovation. If consumers are to use new technologies, the technologies must be reasonably priced relative to alternatives. Otherwise, the acceptance of the new technology may not be viable from the standpoint of the consumer.

According to many researches it is found there is a direct and significant relationship between cost and the adoption of technology. (Seyal, et al., 2006). Higher the benefit-cost ratio, the positive the intention to switch to renewable energy. This scenario is common for solar energy as well. The minimum investment required to install renewable energy can be higher. Rogers et al. (2008) and West et al. (2010) suggested availing economic incentives to ease the financial burden from the users. The summary of these studies report that on the average users are reluctant to pay more than 5\% when compared to their existing energy expenses on conventional energy. This negative attitude may reduce users' intention to switch to renewable energy.

\section{Theories Supporting the Research}

Factors affecting adoption of Solar Energy technology is based on any one or a combination of the following key determinants, as per the literature. Past findings provide guidance to the researcher to draw links between current situations and the literature which play a major role. Different theories have been used to explain the determinants of PV adoption. The most common theories applied in the literature are Diffusion of innovation DIT (Rogers, 1983), Technology Acceptance Model, TAM (Davis, 1989) and Transaction cost economies theory (TCE) (Williamson, 1979)

\section{Hypothesis and Conceptual Framework}

In adoption of solar energy technology from conventional energy technologies is a socially oriented process and an individual's perception plays a vital role in it. (Frankfurt School of Finance \& Management, 2012).The conceptual model for the study was formulated using the concepts of Alam et al. and the findings of Kim et al, and other unique factors that were identified during the literature review as the influencing factors that affect solar energy adoption. Therefore the conceptual framework also focuses on pre-adoption focus on solar energy technology. The integrated model is developed by drawing factors from the three major diffusion models, as well as resent technological literature.

\section{Perceived Ease of Use}

New technology decision implementation is based on its perceived ease of use (Seyal, et al., 2006). The usage policy and maintenance also should be simple to understand. Thus hypothesis 1 (H1) has been formulated as follows.

H1: Perceived ease of use has an impact on solar energy technology usage intention in the Western Province, Sri Lanka

\section{Awareness of the Technology}

Several studies have found that awareness is one of the primary issues in technology adoption (Zografakis, et al., 2010). The information gap makes the acceptance of new 
technology much less likely (Zografakis, et al., 2010). Therefore the second hypothesis (H2) is formulated as follows.

H2: Awareness of the technology has an impact on solar energy technology usage intention in the Western Province, Sri Lanka

\section{Perceived Cost}

Cost for the solar energy consists of an initial investment to set up the machines as well as their periodic maintenance costs. The higher the cost of the technology, the lower its value to users, and the lower its rate of usage (Premkumar, et al., 1997). According to many researches it is found to be a direct and significant relationship between cost and the adoption of technology. (Seyal, et al., 2006). Thus hypothesis 3 (H3) is developed as follows.

H3: Perceived cost has an impact on solar energy technology usage intention in the Western Province, Sri Lanka

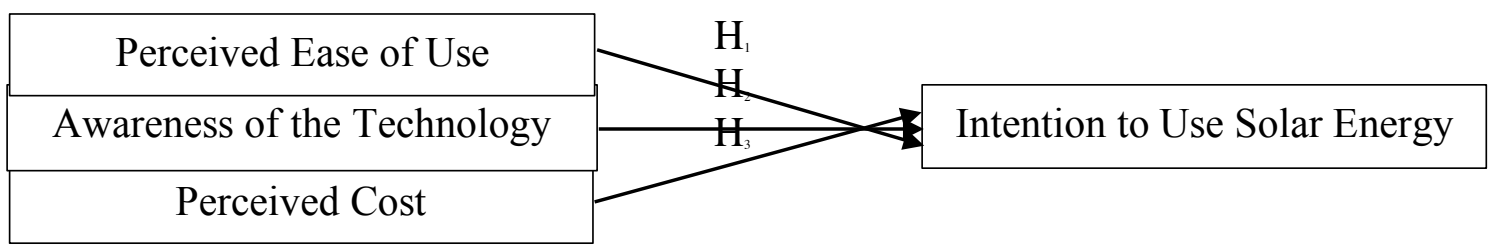

Figure 1: Conceptual framework

\section{Participants and Procedure}

\section{Methodology}

As per the nature of the objectives, this study falls under the positivist paradigm. According to Remenyi the researcher is working with observable social realities and the end result can be generalized to similar circumstances. For this, a simple random sampling technique was employed to draw the sample from the population. The main data collection tool of this study is the questionnaire survey. The data collected on all variables comprise primary data, where the nature of the data mainly involves the perceptions of the respondents. The study administered the questionnaire through an electronic form (email \& google form) as well as printed questionnaires.

More than 1000 questionnaires were distributed randomly among Western province households during a three month period. As a result, a total of 393 (39.3\%) of questionnaires were returned. Of the 393 questionnaires collected, the completed once were used in the analysis. This response rate is considered sufficient considering that, according to (Sekaran, 2003), a response rate of $30 \%$ is acceptable for surveys. Then, the questionnaires were screened and incomplete questionnaires were rejected. Accordingly, 384 questionnaires were forwarded for the data analysis. The data were analyzed using Structural Equation Modeling (SEM) with the aid of AMOS (Analysis of Moment Structures) 23.0.

\section{Measures}

The questionnaire comprises 12 questions to measure the 3 constructs (Perceived ease of use, Awareness of the technology, Perceived cost). The Part (A) includes questions formulated in order to obtain a general understanding of demographic information of the respondents, such as their gender, age, highest education qualification, occupancy status and establishment size. The Part (B) includes adoption factors related information. All questions used in the study were from pretested questions used by other researchers, for example, Kim 
et al and Alam et al. The Part (B) was developed by drawing on existing scales. All constructs were measured using multiple items.

\section{Data Analysis and Results}

A pilot survey was conducted using 30 respondents to identify and eliminate potential problems in the questionnaire design (Malhotra, et al., 2006) and to examine the validity and reliability of the measures used in the questionnaire (Sekaran, et al., 2009). The Cronbach's alpha coefficient of the pilot survey was greater than 0.7 for all constructs which is an acceptable value for a pilot test (Hair, et al., 1998).

After the pilot survey, all data were winsorized at $95 \%$ level to remove outliers and the 384 cases were forwarded for missing value analysis. In this study, there were no missing values in the 384 questionnaires. After missing value data analysis and outlier detection, there were 9 outliers found and removed. The data were tested for multivariate assumptions such as normality, linearity, homoscedasticity and multicollinearity. Normality was tested by skewness and kurtosis where the values were within +2.0 (Garson, 2009). To measure linearity and homoscedasticity normal probability plots (p-plots) and scatter plots were drawn respectively (Hair, et al., 2010) and no deviations were identified. Finally, multicollinearity was assessed using a correlation matrix and all inter-correlation values were less than 0.9. Summarizing the results of multivariate assumptions, all variables were assured of normality, linearity, homoscedasticity and multicollinearity. The Kaiser-MeyerOlkin (KMO) was used to measure the adequacy of the sample of the study. KMO results showed that the sample adequacy of all constructs is greater than 0.5 which indicates that the sample is adequate (Malhotra, et al., 2011). The unidimensionality of all constructs was ensured using Exploratory Factor Analysis (EFA). Cronbach's alpha was used to measure the reliability of all constructs and its value is greater than 0.7 , and thus, it can be concluded that the reliability is established for all constructs. Thereafter, data were forwarded for multivariate analysis.

\section{The Measurement Model}

The measurement model "specifies the indicators for each construct, and enables an assessment of construct validity" (Hair, et al., 2010). Based on the conceptual model, there are 3 latent variables, namely, perceived ease of use, awareness of the technology and perceived cost. As the initial measurement model portrayed a poor fit, the model was improved using modification indices. Stepwise deletion of items below 0.5 factors loading was applied to further refine the initial model. During the modification process, further, covariance was drawn between the error terms of several items for improvement purposes. The final measurement model showed acceptable fit.

Table 1: Model-fit statistics of measurement model

\begin{tabular}{lccccccc}
\hline Absolute & & & & & \multicolumn{2}{c}{ Incremental } & Parsimony \\
\hline CIMIN/DF & GFI & AGFI & RMSEA & IFI & TLI & CFI & PRATIO \\
$\mathbf{1 . 1 6 7}$ & .911 & .875 & .046 & .977 & .973 & .926 & .922 \\
\hline
\end{tabular}

According to Hair et al., (2010), CMIN/DF (X²/df) value close to one and not exceeding 3, Comparative Fit Index (CFI) value close to 1, Tucker- Lewis Index (TLI) value close to 1 
and Root Mean Square Error of Approximation (RMSEA) value of about 0.08 or less indicates a good model fit. As further recommended by Hair et al., (2010), the stated GOF (goodness of fit) indicates must include at least one absolute measure ( $\mathrm{X}^{2} / \mathrm{df} / \mathrm{p}$ value/GFI/RMSR/RMSEA), one incremental measure (NFI/CFI/TLI/RNI) and one parsimony (PRATIO/PCFI/PNFI) fit measure. As shown in Table 1, the CIMIN/DF of the measurement model is close to 1 and below 3 , the RMSEA is 0.046 , thus providing absolute model fit. Also, all incremental and parsimony indices depicted in the Table 1 are close to 1 , assuring satisfactory model fit.

Table 2: Convergent and discriminant validity

\begin{tabular}{|l|c|c|c|c|}
\hline Construct & Measurement & PEU & Awareness & Cost \\
\hline Perceived Ease of Use & PEU & $\mathbf{0 . 7 0 8}$ & 0.004 & 0.002 \\
\hline Awareness & $A w$ & & 0.866 & 0 \\
\hline Cost & Cost & & & $\mathbf{0 . 8 2 2}$ \\
\hline
\end{tabular}

Note: Diagonal entries (in bold) are the square root of AVE for all constructs; sub-diagonal entries are the correlation coefficients estimates between each construct

The Confirmatory Factor Analysis (CFA) was used to further test convergent and discriminant validity of the constructs. As explained by Malhotra \& Dash (2011) 0.5 or higher factor loading and 0.5 or greater Average Variance Extracted (AVE) assures satisfactory convergent validity. In addition, Composite Reliability (CR) must be 0.7 or higher. Generally, discriminant validity can be ensured if the square root of the AVE is larger than the correlation coefficients (Malhotra, et al., 2006) . Further, in ensuring discriminant validity, Maximum Shared Variance (MSV) and Average Shared Variance (ASV) must be less than AVE (Hair, et al., 2010). Moreover, the correlation coefficients among the study constructs do not exceed 0.85 (Kline, 2011). Thus, all the constructs in the study represent different concepts. As all of the above requirements are fulfilled, the convergent and discriminant validities are satisfactory, as shown in Table2.

\section{The structural model}

The structural model defines the relationships among the latent (unobserved) constructs (Byrne, 2010). The proposed structural model is composed of four major latent constructs, of which three are exogenous (perceived ease of use, awareness \& cost) and one endogenous (intention to adoption). All hypotheses were tested at the $95 \%$ confidence level.

Table 3: Model-fit statistics of structural model

\begin{tabular}{lccccccc}
\hline Absolute & & & & \multicolumn{3}{c}{ Incremental } & Parsimony \\
\hline CIMIN/DF & GFI & AGFI & RMSEA & IFI & TLI & CFI & PRATIO \\
$\mathbf{2 . 4 4 0}$ & .868 & .807 & .063 & .931 & .907 & .938 & .904
\end{tabular}

Model fit statistics for the structural model 1 are summarize in Table 3. Accordingly, model fit statistics values of structural model 1 shows a good model fit. (CIMIN/DF 1.148, GFI .903, RMSEA .031, IFI .988, TLI.985, CFI .988). CIMIN/DF is less than 3. GFI is greater than 0.9 and RMSEA shows a good absolute model fit. Further, incremental measures (IFI, TLI, CFI) also shows a good model fit. In addition, parsimony indices confirm the 
satisfactory level of model fit. Hypothesis testing (H1) result of direct path is depicted in Figure 3.

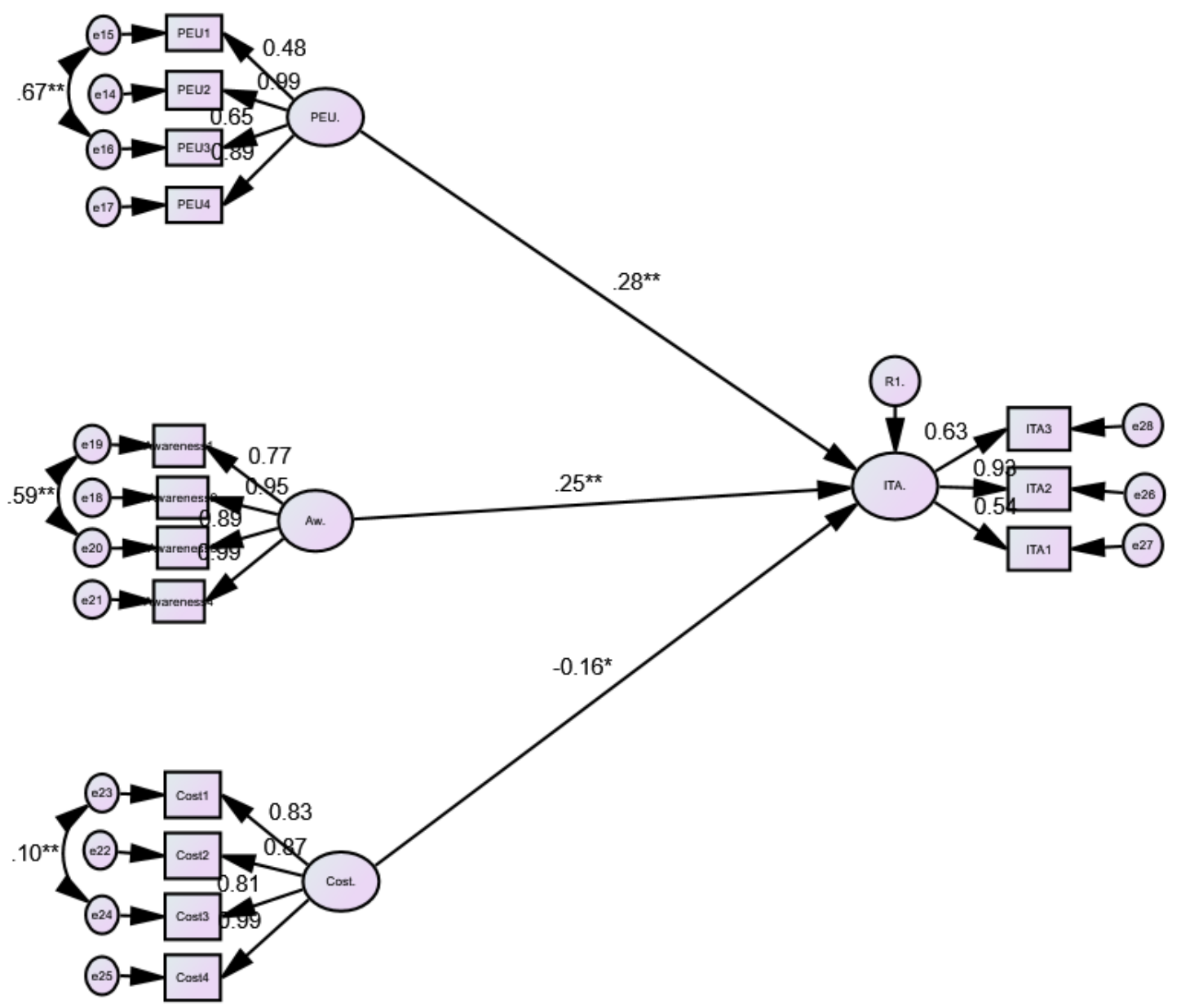

Figure 2 - The structural model

Hypothesis 1 investigated the relationship between perceived ease of use (PEU) and intention to adopt solar energy (ITA). It was hypothesized that there would be a significant effect on the adoption of solar energy technology with perceived ease of use. The results, demonstrated positive and significant paths from perceived ease of use and intention to use solar energy technology. ( $\beta=0.28, p<0.008)$. Thus, hypotheses 1 was supported.

Hypothesis 2 tested the impact with awareness (Aw) and intention to adopt with solar energy technology. (ITA). It was hypothesized that there would be an impact on intention to adoption due to the awareness of the technology. The results suggested that the impact on intention to adoption and awareness on technology are positive and statistically significant $(\beta=0.25, p<0.026)$. Thus, hypothesis 2 was supported.

Hypothesis 3 tested the impact with perceived cost (Cost) and intention to adopt solar energy technology. (ITA). It was hypothesized that there would be an impact on intention to adopt due to the perceived cost of the technology. The results suggested that the impact on intention to adopt and cost of the technology are negative and statistically significant ( $\beta=$ $0.16, p<0.057)$. Thus, hypothesis 3 was supported. 


\section{Discussion}

The first research question addressed the impact solar energy technology has on the perceived ease of use. Four items to measure ease of use were, ease of installation, its understandability, ease of in operation and skills on handling. Perceived ease of use is influenced by users' opinion regarding installation, regular use, maintenance and recycling of the new technology. ( Shah Alam, et al., 2014) It could be argued that the greater the ease of use the new technology is perceived to have, the more likely it is that it would be adopted. (Stepehnson, et al., 2010.) To enhance users' intention to purchase solar energy for household usage, manufacturers and suppliers of solar energy can provide a simple and easily used product. This study also reveals perceived ease of use as the most important factor in adoption.

The second research question addressed the impact solar energy technology has with the awareness of the technology. The results show that awareness of the technology has a big impact of adoption with solar energy technology. Specifically, awareness has a positive influence on adoption of solar energy technology. Consequently people will associate this technology with solar power and recognize it immediately. It will increase people's concern of a recalling power of the technology, recognition, and imaging.

The findings of this study revealed that perceived cost has an impact on intention to adopt solar energy. Further, these results suggest that, perceived cost does have a statistically direct negative effort on adoption of solar energy in the Western province. Specifically, perceived costs reduce the intention to adopt solar technology. Further if the cost is the high adoption of the technology will reduce. These findings are consistent with the findings of previous research in Malaysia, for renewable energy technologies. ( Shah Alam, et al., 2014) and (Alam, et al., 2012)

The study provides inferences made from an instrument that is valid and reliable for the current study's context for evaluating the impact of perceived ease of use, awareness of the technology and perceived cost. Further, the study provides a research framework that identifies significant relationships between perceived ease of use, awareness of the technology and perceived cost with the intention to adopt solar energy technology. This framework provides a foundation and insight for future researchers in the area of solar energy related researches. Although several previous studies discussed the challenges on implementing renewable energy sources they have not spoken about the impact of solar energy technology adoption specifically. Therefore, the instrument developed in this study captures three important factors that affect solar energy technology adoption. The new instrument provides better guideline for researchers in exploring solar energy issues, and thus, can be considered as a strategic management tool.

As per the study findings perceived ease of use is the foremost important factor in influencing intention to use solar energy. Such findings enhance our knowledge and understanding of consumer behavior toward solar energy usage and provide an initiation for solar energy equipment producers to redesign the products.

\section{Managerial Implications}

This study reveals three significant indicators of solar energy intention for household purposes namely perceived ease of use, awareness of the technology and perceived cost. Government authorities such as the Public Utilities Commission of Sri Lanka (PUCSL), Ceylon Electricity Board (CEB), Sustainable Energy Authority (SEA) and other government authorities should create better awareness of the benefits of solar energy usage to encourage the rate of usage among domestic consumers. This can be done using awareness programs 
to the potential consumers in Grama Niladari divisions. This can be performed by introducing introductory sessions for consumers that would allow them to evaluate the benefits of solar energy.

Furthermore, the government can publish solar energy implementation advertisements through television, broadcast through others media like newspapers and radio to raise the public's sense and awareness of the responsibility of environmental protection. It can encourage potential consumers and motivate them to actively participate in green activities and purchase as eco-friendly energy source. On the other hand, government or responsible authorities can held some green energy source marketing campaigns to encourage potential consumers in environmental issues. This will explain to them the impact and consequences of their contribution in those activities to their future generation.

To receive more positive responses of solar energy usage, it is recommended that these authorities provide a loan systems to give financial support for them at the initiation. This could also be done through a loan from the state banking corporations. There is a loan scheme already providing a loan facility conducted by the intermediation of the CEB and that could also be widened with the help of commercial banks as well.

Government authorities could establish a connection with current solar energy users and obtain continuous feedback from them to identify problem areas and diagnose them to take necessary actions. Technical advice could be provided free of charge except the service which solar companies are providing. Enhancing standards of solar power is another way of establishing its use.

Solar energy schemes of metering can be used to offset the construction and operation expenses and pollution occurring due to conventional power plants. In power generation, renewable energy sources produce less carbon while non-renewable energy sources or fossil fuel power plants emit extremely high level of greenhouse gases. There can be a new option of selling carbon credits, by this total carbon emission saving through promoting solar energy. Therefore this can be calculated and converted into carbon credits and the utility can generate additional revenues by selling these carbon credits.

Net metering provides substantial economic benefits in terms of jobs, income and investment.Net metering increases demand for solar energy systems, which in turn creates jobs for the designers, installers, electricians and manufacturers who work in the solar supply chain. The employment opportunities are developed ranging from skilled laborers to customer service and sales representatives. Net metering encourages consumers to play an active role in clean energy production, which helps to protect the environment and helps preserve natural energy resources.

There are heavy electricity users who always have to pay excessive rates for the last blocks of units $(\mathrm{kWh})$ they consume. Solar energy consumption is a viable solution for them. Although the initial investment is much higher to install a new renewable generation facility, the payback period would be very low for heavy electricity users. Using solar power sources for electricity generation reduces the need for expensive and polluting fossil power generation. Their utilization can result in a net reduction in emissions of air pollutants that affect air quality.

\section{Limitations and Future Directions}

Although this research has made significant contributions from both theoretical and practical points of views, it also has some limitations, which are described below. The examination of those limitations will assist future researchers to work around them. 
The main limitation in this study is geographical unfairness. The population of the Western province was taken into consideration and compared, to get an idea for the whole of Sri Lanka. However, the findings of this study may not represent the views of all potential consumers of Sri Lanka due to the geographical differences and social cultural differences. Their life style differences may also affect. Due to the limited number of observations collected, data may be limited to the area tested through the survey questionnaire. New mailing lists and research methods can be used to improve the response rate. The way we collected data for this research was through google forms and distributed forms among Western province households. But if its' possible to distribute questionnaires among random households in a more appropriate manner with high frequency, that would be more effective.

\section{Conclusions and Recommendations}

The research has shown the three important factors that have an impact on solar energy adoption. The analytical results prove that there is an impact on solar energy adoption with all the three factors. Generally all the results gained were are consistent with previous studies. It would be interesting to study the same factors with a more average solar energy user population with different user patterns.

The aim of this study is to examine the factors affecting the intention to use solar energy in Western province households. The study also enhances our knowledge and expands it about solar energy as a source of green energy for small-scale household use in urban areas. This examines the rationales of accepting or rejecting the use of alternative energy sources i.e solar. From a managerial perspective, these findings provide support for investment decisions for the investors who are interested in the green energy concept with the environment friendliness, as well as for decisions concerning the improvement of renewable energy, which could be taken into consideration for residential needs.

This research was performed under a theoretical framework that was developed based on theories of Technology acceptance model (TAM), Diffusion of innovation (DOI) and Transaction cost economies (TCE) theory. The data analysis interpreted by AMOS shows that perceived ease of use and awareness are the most important elements of intention to use solar energy for household purposes. As a good sign of improvement the Sri Lankan government has focused its attention on developing renewable energy technologies in Sri Lanka like wind, solar and geo thermal. This is a good sign for future endeavours in green energy.

Regardless of certain limitations, this research has put forward some important contributions. Firstly the researcher reviewed the existing literature in the solar energy adoption area and found there is a small gap for a research which has not yet been filled by any researcher. Then combining a few established theories alone with the literature a theoretical framework was built. We lastly examined the factors contributing to the usage intention of solar energy.

\section{References}

Alam , S. S. \& Rashid, M., (2012). Intention to use renewable energy mediating role of attitude. Energy Research Journal, 3(2), 37-44.

Alam, S. S. et al., (2014). Small scale household renewable energy usage intention: Theoritical development and empirical settings. Renewable Energy, 68, 255-263.

Alam, S. S. \& Mamunur, . R., (2012). Intention to use renewable energy: mediating role of attitude. Energy Research Journal, 3(2), 37-44. 
Authority, S. E., (2016), "Renewables:surya bala sangramaya," available at: http://www.energy.gov.lk/ (accessed 20 September 2017).

Byrne, B. M., 2010. Structural equation modeling with AMOS. 2nd edition ed. New York: Routledge.

Ceylon Electricity Board , (2016). CEB Statistical Digest, Colombo: Ceylon Electricity Board.

Ceylon Electricity Board, (2014). CEB Annual Report, s.l.: Ceylon Electricity Board.

Davis, F. D., (1989). Perceived usefullnesss,perceived ease of use and user acceptance of Information Technology. MIS Quarterly,University of Michigan, p. 319.

Department of Meterology, (2016), "Department of Meterology," available at: http://www.meteo.gov.lk/index.php?lang=en (accessed 3 August 2017).

EIA, (2016). The International Energy Outlook, Washington: U.S. Energy Information Administration.

Fishbein, M. \& Ajzen, I., (1975). Belief, attitude, intention, and behaviour: An introduction to theory and research., s.1.: MA: Addison-Wesley.

Frankfurt School of Finance \& Management, (2012). Global trends in renewable energy investment, Bloomberg: Frankfurt School- UNEP Collaborating Centre for Climate \& Sustainable Energy Finance..

Garson, G., (2009). Quantitative research in public administration. s.1.:s.n.

Hair, J., Black, W., Babin, B. \& Anderson, R., (2010). Multivariate data analysis: A global perspective. $7^{\text {th }}$ Edition ed. s.l.:Pearson.

Hair, J. J., Anderson, . R., Tatham, . R. \& Black, W., (1998). Multivariate Data Analysis. 5 th edition ed. Upper Saddle River, NJ: Prentice Hall.

Howard, J. \& Moore, W., (2002). Changes in consumer Behavior Over the Product Life Cycle. Marshfield: Pitman.

IEA, (2006). Renewable Energy: RD \& D Priorities, Insights from IEA Technology progrems, France: International Energy Agency(IEA).

Katinas, V., Karbauskaitè, J., Perednis, E. \& Valančius, R., (2013). Efficiency analysis of combined biomass and solar energy in Lithuania. Clean technology and environmental policy, 15(4), 667-676.

Kim, H. et al., (2014). An integrated adoption model of solar energy technologies in South Korea. Renewable energy, 523-531.

Kline, R., (2011). Principles and practice of structural equation modeling. 3rd Edition ed. s.1.:The Guilford Press..

Malhotra, N. \& Dash, S., (2011). Marketing Research: An applied Orientation. 6th Edition ed. s.1.:Pearson Education.

Malhotra, N. \& Peterson, M., (2006). Basic marketing research. International Edition ed. s.l.:s.n.

Premkumar, G., Ramamurthy, . K. \& Crum, M. R., (1997). Determinants of EDI Adoption in the Transportation Industry. European Journal of Information Systems, 6(2), 107121.

Purohit, I. \& Purohit, P., (2017). Technical and economic potential of concentrating solar thermal power generation in India. Renewable and Sustainable Energy Reviews, 78, 648-667.

Rogers , E. \& Shoemaker, F., (2001). Communications in Innovation, New York: Free press. Rogers, E. M., (1983). Diffusion of Innovations, New York: The free press. 
Sekaran, U., (2003). Research methods for business: A skill-building approach. 4th edition ed. s.l.: John Wiley \& Sons, Inc..

Sekaran, U. \& Bougie, M., (2009). Research methods for business: A skill building approach. UK: John Wiley \& Sons..

Seyal, A. H. \& Rahim, M., (2006). A preliminary investigation of electronic data exchange adoption in Bruneian small business organizations. Electronic Journal of Information Systems in Developing Countries, 24(4), 1-21.

Shah Alam, S., Hashim, N. H. N., Rashid, M. \& Omar, N. A., (2014). Small-scale households renewable energy usage intention:Theoretical development and empirical settings. Renewable Energy, 68, 255-263.

Spence, M. \& Brucks, M., (1997). The moderating effects of problem characteristics on expert's and novice's judgements.. Journal of Marketing Research, Volume 34, p. 233-247.

Stepehnson , J. \& Loannou , M., (2010).. Social acceptance of renewable electricity developments in New Zealand., s.l.: Centre for the Study of Agriculture, Food and Environment, University of Otago: Energy Efficiency and Conservation Authority.

Stephenson , J. \& Ioannou, M., (2010). SOCIAL ACCEPTANCEOF RENEWABLE ELECTRICITY DEVELOPMENTS IN NEW ZEALAND, Otago: Centre for the Study of Agriculture, Food and Environment,University of Otago.

Sustainable Energy Authority, (2011). On grid renewable energy develpoment, s.1.: Sustainable Energy Authority.

Sustainable Energy Authority, (2017), "Renewables:Sri Lanka Sustainable Energy Authority," available at: http://www.energy.gov.lk/ (accessed 10 March 2017).

Taylor, M., Daniel, K., Ilas, A. \& Young, E., (2014). Renewable Power generation cost, s.1.: IRENA.

Williamson, O., (1979). Transaction Cost Economics:The governance of contractual relations. Journal of Law and economics, Issue 22, pp. 233-262.

Zografakis, N. et al., (2010). Renewable and Sustainable Energy Reviews, 14(3), pp. 10881095. 